
$\$$ Research Square
Preprints are preliminary reports that have not undergone peer review.
They should not be considered conclusive, used to inform clinical practice, or referenced by the media as validated information.

\title{
Early initiation of breastfeeding practice and associated factors among mothers of children aged less than six months of old in Mizan-Aman town, southwest Ethiopia, 2018
}

\author{
Tesfa Birlew ( $\nabla$ tesfabirlew@yahoo.com ) \\ Debre Markos University College of Health Science https://orcid.org/0000-0003-3745-173X \\ Muluken Amare \\ Wollo University
}

Research article

Keywords: Early Initiation of Breastfeeding, Timely Initiation of Breastfeeding, Early/Timely Initiation of Breastfeeding Practice, Optimal Breastfeeding, Mizan-Aman, Ethiopia

Posted Date: September 25th, 2020

DOl: https://doi.org/10.21203/rs.3.rs-72239/v1

License: (c) (1) This work is licensed under a Creative Commons Attribution 4.0 International License.

Read Full License 


\section{Abstract}

\section{Background}

Ethiopian government implemented baby-friendly hospital initiative and community integrated management of childhood illnesses program. Despite early initiation of breastfeeding taken as a key tool for tackling neonatal mortality, EIBF is still low and most of the neonatal mortalities were existed due to delayed initiation of breastfeeding in Ethiopia in general and the practice is not well documented in South West Ethiopia in particular. Therefore, this study aimed to assess early initiation of breastfeeding practice and associated factors among mothers of children aged less than six months of old in Mizan-Aman town, southwest Ethiopia.

Methods

A community-based cross-sectional study was employed from April 15 to May 15, 2018. A total of 487 recently delivered mothers were included. The data was collected through face to face interview by using a pre-tested and structured questionnaire. Binary and multivariable logistic regression analysis were employed and p-value $<0.05$ was identified as statistically significant factors, and the quality of the data were assured, checked, coded, cleaned and entered in Epi-Info version 3.5.3 and

exported to SPSS version 25 for the analysis.

Result

The prevalence of timely initiation of breast feeding was 296(64.50\%) in Mizan- Aman Town. Mothers who had < 24 months birth spacing history 1.85(AOR: 95\% Cl: 1.22, 2.81), mothers' income level between 1001-1500 Ethiopian Birr 2.21 (AOR: 95\% Cl: 1.12, 4.37), Primipara mothers 2.00 (AOR: 95\% Cl: 1.24, 3.23) and home delivery $2.76(\mathrm{AOR}: 95 \% \mathrm{Cl}: 1.24,6.14$ ) were important positive predictors for timely initiation of breast feeding. Furthermore, Government employee and merchant mother by occupation was found to be protective factors.

Conclusion and recommendation

The practice of early initiation of breast feeding was suboptimal and still below the national average. Intervention at the community and facility level should paid special attention.

\section{Background}

Early initiation of breastfeeding is putting newborns to the breast within the first hour of life and saves lives and provides benefits that last a lifelong [1].

Globally, an estimated 2.5 million newborns died in the first month of life in 2018, approximately 7,000 every day. $99 \%$ of all neonatal deaths occur in in low and lower-middle income countries. If the problem is 
left untreated, more than 60 countries will miss the target for neonatal mortality (12 deaths or fewer per 1,000 live births) by 2030[2]. In Ethiopia, 2019 EMDHS reveals that the neonatal mortality rates were 30 deaths per 1,000 live births [3].

Worldwide in 2017, it is estimated that 78 million newborns delayed more than one hour to be put to the breast. which means that $42 \%$ or only two out of five newborns, the majority born in low- and middleincome countries, were initiated breast feeding within the first hour of life. The practice varies worldwide from (35\%) in the Middle East and North Africa to (65\%) in Eastern and Southern Africa. Ethiopia found in eastern Africa region, the practice of early initiation of breast feeding in 2016 was 73.3\%, slight improvement has been made from 2005 practice 66.2\% [4].

Early initiation of breast feeding has beneficial effect on baby's as well as maternal health like: save more than 800,000 children each year, increase cognitive development, prevent overweight and obesity, boosts immunity system and protect against all half of diarrheal and one third of respiratory infectious diseases [5]. Indeed, mothers benefited from breast feeding involving: a lower risk of 20,000 breast cancer death, ovarian cancer, improve birth spacing, post-partum hemorrhage, depression, type 2 diabetes and saved $\$ 300$ billion to the global economy each year [5-7].

The longer newborns delayed for breast feeding, the greater their risk of death. New studies revealed that when compared with newborns who initiated breastfeeding within an hour of birth, the risk of dying during neonatal period is 33\% higher for those who initiated 2-23 hours after birth, and was two times higher for those who initiated one day or longer after birth [8].

There are many factors which determine the practice of early initiation of breast feeding like: outdated practices in health facilities, lack of knowledge about breastfeeding after a caesarean section, cultural practices like prelacteal feeding, Massive missed opportunity, skilled birth attendants, place of deliveries, Programme and policy-related factors and Access to antenatal care [4, 9-11].

Despite Ethiopia have been implemented different programs on optimal breast feeding as key tool to tackle neonatal and infant mortality, yet not meet the desired outcome [12-14]. Although the importance of early breast-feeding practice, limited information is documented in southwest Ethiopia. Therefore, this study was attempted to fill this information gap and come up with recommendation on possible intervention for timely initiation of breast-feeding improvement and associated factors in Mizan -Aman town, southwest Ethiopia.

\section{Methods}

\section{Study setting and study period}

The study conducted in Mizan-Aman town, the capital town of Bench Maji Zone, is situated $561 \mathrm{Km}$ south west of Addis Ababa capital town of Ethiopia, from April 15 to May 15/2018. The town is administratively structured by 7 kebeles and has a total population of 49,590 of which 26,392 are males 
and 23,197 are females. Out of all female population 11, 554 of them are women in the reproductive age group (15-49 years). About $(1,582)$ or $3.9 \%$ of the total population is accounted by children less than one years of age. It has one public hospital, one health center, three health post, 10 private health institution and 17 drug stores.

\section{Study design}

A community based cross-sectional study was employed in Mizan-Aman town

\section{Sampling size determination}

The sample size was determined using single population proportion formula. The following assumption were considered: $95 \%$ level of confidence, $5 \%$ margin of error and $50 \%$ of women estimated to be initiated breast feeding within one hour. Since population size was 1582 , which is less than 10,000 , sample size was adjusted using correction formula, 2 design effects were considered and by adding $5 \%$ non-response rate, the final sample size became 487 .

\section{Sampling procedure}

Since it is multistage among the two sub-cities (Mizan and Aman sub-city), Mizan sub-city was selected by lottery method. Among five kebeles in the selected sub city, three of them were selected by lottery method. proportional allocation to size was done in each 3 selected kebeles. Then after a systematic random sampling technique was employed at the kebele level by using health extension family record book as a sample frame. Following random selection of the first household with a woman who fulfilled the selection criteria, subsequent households with women meeting the criteria were selected from every three house until the desired sample size was reached in each kebele. For households with more than one eligible woman, one of the women was chosen using a lottery method.

\section{Data collection tools and procedures}

The data collection tool was adapted from Ethiopian Demographic and Health Survey (EDHS) 2016 document [15] and translated into local Amharic languages. Training was given for data collectors and supervisors how to make face to face interview and assuring the quality of data. pre-test was done in $5 \%$ of the sample size in Tapi town.

\section{Operational definition}

Early initiation of breastfeeding: Is putting newborns to the breast within the first hour of life [1].

Level of information about breastfeeding: Those mothers who mentioned $\geq 2$ components of breastfeeding information (1. Benefits of breast feeding 2. positioning of the baby 3. exclusive breast feeding 4 . managements of breast problem 5. Expression of breast milk) were considered as having good level of information and mentioned $\leq 1$ components of information were considered as the counterpart [15]. 


\section{Data quality control}

Prior to data collection period, data collectors trained about the objective of the research. The PI was given the training about the objective of the study and data collection system by using semi-structured questionnaires in a one-day period. The questionnaires would prepare in English, translated into Amharic and back translated into English to check consistency. Pre-test carried out on Tapi town to familiarize the interviewer with the tools and to check the coherence. To keep the quality of data, principal investigator was checking the questionnaires for its completeness in each day.

\section{Data processing and analysis}

The data was cleaned, coded and entered in to Epi Info version 3.5.3 and exported to SPSS version 25 statistical package for analysis. Descriptive statistics was computed to determine the magnitude of early initiation of breast feeding. Furthermore, bivariate logistic regression and multivariate analysis with $95 \%$ confident interval were done in order to determine predictors of early initiation of breast feeding. Variable with a $P$ value of $<0.05$ was taken as the criterion for statistical significance.

\section{Results}

A total of 487 mother-child pairs were included in the study, resulting in a response rate of $459(94.3 \%)$.

\section{Sociodemographic characteristics of mothers and infants}

Of the total respondents, the majority: $279(60.8 \%)$ had $\geq 4$ number of family, $173(37.7 \%)$ were $20-$ 24 years of age mothers, $435(94.8 \%)$ married, $157(34.7 \%)$ had primary level of education(1-8 grade), $186(40.5 \%)$ orthodox in religion, $134(29.2 \%)$ were Amhara in ethnicity, 268(58.4\%) were house wife in occupation, 302(65.8\%) had gotten $<500$ Eth Birr/month, 247(50.9\%) infants were male, $215(46.8 \%)$ were first order/first child for their family and were no previous birth (Table 1). 
Table 1

Socio-demographic characteristics of mothers of children aged less six months in Mizan Aman town, south west Ethiopia, $2018(\mathrm{~N}=459)$

\begin{tabular}{|c|c|c|}
\hline Demographic variable & Frequency $(N=485)$ & Percentage (\%) \\
\hline \multicolumn{3}{|l|}{ Age of mothers in years } \\
\hline $15-19$ & 47 & 10.2 \\
\hline $20-24$ & 173 & 37.7 \\
\hline $25-29$ & 155 & 33.8 \\
\hline $30-34$ & 48 & 10.5 \\
\hline $35-49$ & 36 & 7.8 \\
\hline \multicolumn{3}{|l|}{ Maternal marital status } \\
\hline Single & 19 & 4.1 \\
\hline Married & 435 & 94.8 \\
\hline Divorced & 5 & 1.1 \\
\hline \multicolumn{3}{|l|}{ Maternal educational level } \\
\hline unable to read and write & 100 & 21.8 \\
\hline able to read and write & 35 & 7.6 \\
\hline Primary $(1-8)$ & 157 & 34.2 \\
\hline Secondary (9-12) & 99 & 21.6 \\
\hline college and above & 68 & 14.8 \\
\hline \multicolumn{3}{|l|}{ Religion } \\
\hline Orthodox & 186 & 40.5 \\
\hline Protestant & 170 & 37.1 \\
\hline Muslim & 103 & 22.4 \\
\hline \multicolumn{3}{|l|}{ Maternal ethnicity } \\
\hline Bench & 106 & 23.1 \\
\hline Kaffa & 101 & 22 \\
\hline Amhara & 134 & 29.2 \\
\hline Oromo & 43 & 9.4 \\
\hline Others & 75 & 16.3 \\
\hline
\end{tabular}




\begin{tabular}{|c|c|c|}
\hline Demographic variable & Frequency $(\mathrm{N}=485)$ & Percentage (\%) \\
\hline \multicolumn{3}{|l|}{ Maternal occupation } \\
\hline house wife & 268 & 58.4 \\
\hline government employee & 55 & 12 \\
\hline Merchant & 55 & 12 \\
\hline Farmers & 45 & 9.8 \\
\hline Private employee & 36 & 7.8 \\
\hline \multicolumn{3}{|l|}{ Mothers income level } \\
\hline$<500$ ETH Birr & 302 & 65.8 \\
\hline 500-1000 ETH Birr & 74 & 16.1 \\
\hline 1001-1500 ETH Birr & 18 & 3.9 \\
\hline >1500 ETH Birr & 65 & 14.2 \\
\hline \multicolumn{3}{|c|}{ Age of the infant in month } \\
\hline$<1$ & 27 & 5.9 \\
\hline $1-6$ & 432 & 94.1 \\
\hline \multicolumn{3}{|l|}{ Sex of the infant } \\
\hline Male & 247 & 50.9 \\
\hline Female & 238 & 49.1 \\
\hline \multicolumn{3}{|l|}{ Birth order of the infant } \\
\hline First & 215 & 46.8 \\
\hline $2-3$ & 185 & 40.3 \\
\hline $4-6$ & 51 & 11.1 \\
\hline$\geq 7$ & 8 & 1.8 \\
\hline \multicolumn{3}{|c|}{ Birth spacing of the infant } \\
\hline No previous birth & 216 & 47.1 \\
\hline$<24$ month & 30 & 6.5 \\
\hline$\geq 24$ month & 213 & 46.4 \\
\hline \multicolumn{3}{|c|}{ No of children in the family } \\
\hline$\leq 3$ & 398 & 86.7 \\
\hline
\end{tabular}




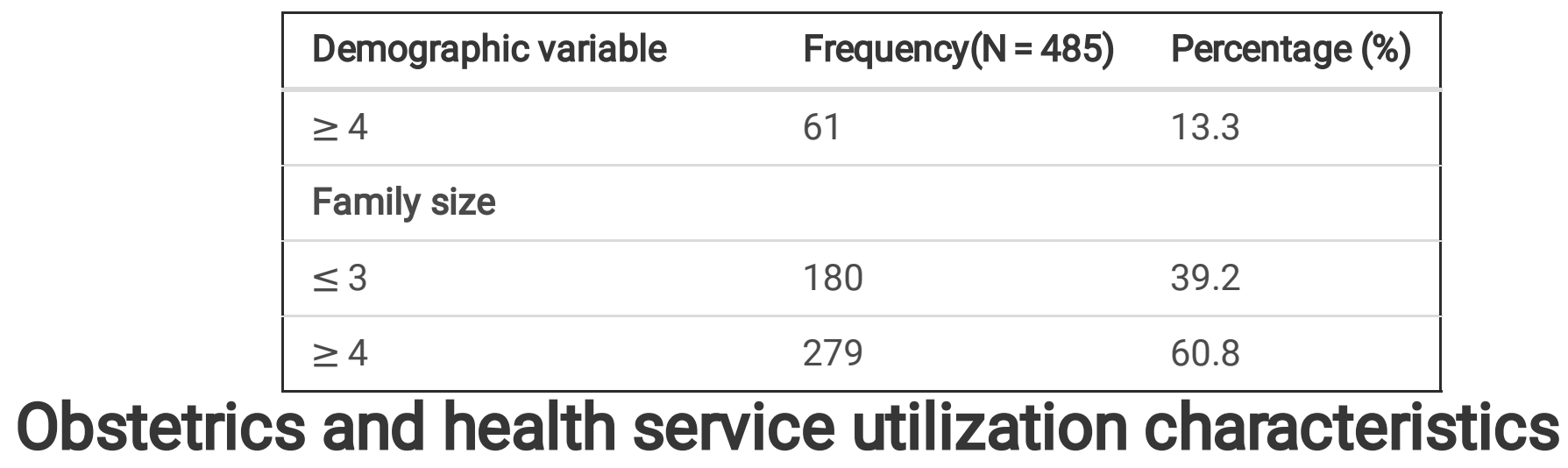

The majority of the total respondents, $240(52.3 \%)$ were Multipara mothers, while 219 (47.7\%) were primipara. Regarding maternal health service utilization; the majority of respondents $446(97.2 \%)$ were attending ANC, 304(66.2\%) attended ANC four and more times, 263(57.3\%) had gotten breast feeding Counseling at ANC Clinic, 415(90.4\%) delivered their child at health facility, 413(90\%) delivered through normal spontaneous and their delivery was assisted by health professional (Table 2). 
Table 2

obstetrics and maternal health service utilization characteristics among mothers of children less than six months of age in Mizan Aman town, southwest Ethiopia, 2018(N =459)

\begin{tabular}{|c|c|c|}
\hline Variables & Frequency $(\mathrm{N}=459)$ & Percentage (\%) \\
\hline \multicolumn{3}{|l|}{ Attending Antenatal care $(n=459)$} \\
\hline Yes & 446 & 97.2 \\
\hline No & 13 & 2.8 \\
\hline \multicolumn{3}{|c|}{ Utilization of Antenatal care $(n=446)$} \\
\hline 1 time & 9 & 2 \\
\hline $2-3$ times & 133 & 29 \\
\hline$\geq 4$ & 304 & 66.2 \\
\hline \multicolumn{3}{|c|}{ Get breast feeding Counseling at ANC Clinic $(n=446)$} \\
\hline Yes & 263 & 57.3 \\
\hline No & 183 & 40 \\
\hline \multicolumn{3}{|l|}{ Place of Delivery $(n=459)$} \\
\hline Health Facility & 415 & 90.4 \\
\hline At Home & 49 & 9.6 \\
\hline \multicolumn{3}{|l|}{ Mode of Delivery $(n=459)$} \\
\hline CS Delivery & 46 & 10 \\
\hline Normal Spontaneous Delivery & 413 & 90 \\
\hline \multicolumn{3}{|l|}{ Delivery Attendant(n = 459) } \\
\hline Health Professionals & 413 & 90 \\
\hline Traditional Birth Attendants & 46 & 10 \\
\hline
\end{tabular}

\section{Initiation of breast-feeding practice}

All mothers have breastfed ever their current infant. out of those, 296(64.5\%) newborns were put to the breast within one hour and 163(35.5\%) were delayed initiation breast feeding more than one hour (Fig. 1). The main reason for delayed initiation of breast feeding were $31(6.75 \%)$ breast feeding problem and 8 (1.7\%) due to maternal medical illness.

\section{Knowledge of mother about breastfeeding}


The majority, 274(59.7\%) of mothers have good level of information about breast feeding, while $185(40.3 \%)$ have poor level of information. The majority, $413(90 \%)$ of respondents mentioned beneficial of breast-feeding, while only $31(6.5 \%)$ of mothers mention about expressed breast milk.

\section{Factors associated with timely initiation of breastfeeding}

In multivariate analysis; Mothers who had < 24 months birth spacing history 1.851(AOR: $95 \%$ Cl: 1.218, 2.813), mothers' income between 1001-1500 Birr 2.207 (AOR: 95\% Cl: 1.115, 4.368), Primipara mothers 2.002 (AOR: $95 \%$ Cl: 1.241, 3.229) and home delivery 2.755(AOR: 95\% Cl: 1.237, 6.135) were important positive factors for timely initiation of breast feeding. indeed, gov't employee and merchant mother by occupation and were found to be protective factors for timely initiation of breast feeding, respectively (Table 3). 
Table 3

Factors associated with early initiation of breast-feeding among mothers of children aged less than 6 months in Mizan-Aman town, southwest Ethiopia, 2018( $\mathrm{n}=459)$

\begin{tabular}{|c|c|c|c|c|}
\hline \multirow[t]{2}{*}{ Variables } & \multicolumn{2}{|c|}{ Timely initiation of BF } & \multirow{2}{*}{$\begin{array}{l}\text { Crude odds ratio (C.I: } \\
95 \%)\end{array}$} & \multirow{2}{*}{$\begin{array}{l}\text { Adjusting odds ratio } \\
\text { (C.l: } 95 \%)\end{array}$} \\
\hline & Yes & No & & \\
\hline \multicolumn{5}{|l|}{ Occupation } \\
\hline Private employee & $19(52.8 \%)$ & $17(47.2 \%)$ & 1 & 1 \\
\hline $\begin{array}{l}\text { Government } \\
\text { employee }\end{array}$ & $41(74.5 \%)$ & $14(25.5 \%)$ & $0.137(.024, .785)$ * & $0.074(.006, .867)$ * \\
\hline Merchant & $35(63.6 \%)$ & $20(36.4 \%)$ & $0.229(.041,1.289)$ & $0.079(.007, .933)$ * \\
\hline House wife & $176(65.7 \%)$ & $92(34.3 \%)$ & $0.029(040,1.099)$ & $.212(.35,1.275)$ \\
\hline Farmer & $25(55.6 \%)$ & $20(44.4 \%)$ & $.320(.056,1.827)$ & $.364(0.55,2.416)$ \\
\hline \multicolumn{5}{|l|}{ Income level } \\
\hline$<500$ ETH Birr & $187(61.9 \%)$ & $115(38.1 \%)$ & $3.533(1.152,10.841)$ & $3.172(1.023,9.836)$ \\
\hline 500-1000 ETH Birr & $46(62.2 \%)$ & $28(37.8 \%)$ & $2.688(1.221,5.883)$ * & $2.235(1.003,4.979)$ * \\
\hline $\begin{array}{l}\text { 1001-1500 ETH } \\
\text { Birr }\end{array}$ & $10(55.6 \%)$ & $8(44.4 \%)$ & $2.716(1.392,5.299)$ * & $2.207(1.115,4.368)$ * \\
\hline > 1500 ETH Birr & $53(81.5 \%)$ & $12(18.5 \%)$ & 1 & 1 \\
\hline \multicolumn{5}{|l|}{ Birth space } \\
\hline No previous birth & $125(57.9 \%)$ & $91(42.1 \%)$ & $.693(.283,1.696)$ & $0.709(.28,1752)$ \\
\hline$<24$ months & $23(76.7 \%)$ & $7(23.3 \%)$ & $1.658(1.114,2.467)$ * & $1.851(1.218,2.813)$ * \\
\hline$\geq 24$ months & $148(69.5 \%)$ & $65(30.5 \%)$ & 1 & 1 \\
\hline \multicolumn{5}{|l|}{ Gave live birth } \\
\hline Primipara & $127(58 \%)$ & $92(42 \%)$ & $1.724(1.172,2.536)$ * & $2.002(1.241,3.229)$ * \\
\hline Multipara & $169(70.4 \%)$ & $71(29.6 \%)$ & 1 & 1 \\
\hline \multicolumn{5}{|l|}{ Place of delivery } \\
\hline Health facility & $278(66.8 \%)$ & $138(33.2 \%)$ & 1 & 1 \\
\hline At home & $18(41.9 \%)$ & $25(58.1 \%)$ & $2.798(1.476,5.304)$ * & $2.755(1.237,6.135)$ * \\
\hline
\end{tabular}

*Statistically significant at $p<0.05$ in the crude analysis and after adjusting for selected confounding variables. 
our study revealed that Breastfeeding practices were sub-optimal in the study setting due to the delayed initiation of breast feeding. The prevalence of timely initiation breast feeding in Mizan-Aman town is found to be $64.5 \%$. This figure is consistent with study findings which were conducted in Debre Berhan town, Kenya, Lesotho and Jamaica $(62.6 \%, 62.2 \%, 65.3 \%$ and $64.7 \%$ respectively) $[16,11,17,21]$.

The practice of early initiation of breast feeding in our study area was higher than study from in Zimbabwe (58.3\%) ,south Gondar (54.7\%),Axum Town (41.6\%) and Goba district (52.4\%) respectively[17, $18,19,20]$.this difference could be due to study setting, some of them were from rural side, population character, when the study subjects are those mother of children more than 6 months of age they might not recall well when to start to initiate breast feeding, information and health service utilization and socio economic difference between the referenced subject and the study place.

Higher rate of timely initiation of breast feeding was reported from Malawi (76.9\%) [21], Bahirdar city (75.4\%) [22], Debre Tabor town (76.8\%) [23] and Motta town (76.8\%) respectively [21, 22, 23, 24]. the difference might be due to methodological difference, socioeconomic, cultural difference and access to health service.

Mothers' income level between 1001-1500 Eth Birr were two times (AOR: 95\% Cl: 1.115, 4.368) more likely initiated breast feeding within one hour than mothers' income $>1500$ Eth Birr. While, this study is contradicted with Debre Berhan town [16], those mothers' income level > 1969 Eth Birr were more likely initiated early breast feeding. This difference might be due to having higher income and being sophisticated city women, empowers the women to make medical decision. they can afford and prefers elective Cesarean section delivery in order to avoid labor pain. This in turns leads to delayed initiation of breast feeding. Indeed, this is supported by evidence in this study, gov't employee and merchant mother by occupation, the majority of them have gotten > $1500 \mathrm{ETH}$ Birr/month, were 0.074 (AOR: $95 \% \mathrm{Cl}: .006$, .867 ) and 0.079 (AOR: $95 \% \mathrm{Cl}: .007, .933$ ) less likely to initiate breast feeding within one hour.

Our study revealed that the odds of timely initiation of breast feeding among primipara mothers were two times (AOR $=2.002,95 \% \mathrm{Cl}: 1.241,3.229)$ higher than their counterpart. This is similar with report from Malawi [21], while contradicted with report from south Gondar [16]. Since primipara mothers are less experienced, might fear of complication. Therefore, for the sake of their infant health, they might seek frequent medical advice from the care providers. This implies that having good level of information about newborn care will result putting their newborn to breast early.

Our study showed that the odds of early initiation of breast feeding among home delivered mothers were nearly three times $(\mathrm{AOR}=2.755,95 \% \mathrm{Cl}: 1.237,6.135)$ higher than as compared as had institutional delivery. This is contradicted with report from Gurage zone Gunchere woreda [25], Arsi Tiyo woreda [26], Malawi [21], Bahirdar city [22] and Motta town [24], respectively. This might be due to more births take place in health institutions with skilled providers doesn't mean necessarily will result optimal breastfeeding practice. Rather, missed opportunities, having less committed skilled attendant and having not appropriately trained staff with essential newborn care will result negative effect between institutional delivery and early initiation of breast feeding. This implies that quality of care should be improved in 
order to have positive relation between institutional delivery and putting newborns to breast within onehour practice.

\section{Strength and limitation of the study}

This study is a community based and tried to represent and made generalization by involving relatively adequate number of study subject. Tried to reduce recall bias by involving only those mother of infant age less than 6 months. But it will share the cross-sectional design limitations.

\section{Conclusion And Recommendation}

The practice of early initiation of breast feeding was sub-optimal and below the national average in study place. Mothers who had < 24 months birth spacing history, mothers' income between 1001-1500 Birr, Primipara mothers and home delivery. Risky groups like; multipara mothers, high income level mothers and having $\geq 24$ months birth spacing practice shall be given special attention and provided intensive health education program at the community and facility level. Improving quality of care in health facilities through providing training and support for staff members on maternal and newborn care. Furthermore, improve access to skilled breastfeeding counselling for all mothers are recommended. The Future researcher shall be employed follow up and mixed study.

\section{Abbreviations}

AOR: Adjusted Odds Ratio; ANC:Ante Natal Care; CS:Cesarean Section; EDHS:Ethiopia Demographic and Health Survey; EIBF:Early Initiation of Breastfeeding; EMDHS:Ethiopia Mini Demographic and Health Survey; SDG:Sustainable Developmental Growth; WHO:World Health Organization

\section{Declarations}

\section{Ethics approval and consent to participate}

Ethical clearance was secured from Wollo University, college of medicine and health science (Ref. No:SL./No/205/16/2018) research and community service office to Mizan-Aman town health unit. Permission letters was obtained from Mizan-Aman town health unit and respective kebeles. Study participant mothers were asked by explaining the objective of the study and its significance. Since the research topics is less sensitive/ no more principal risk would be potential harm unless breach of confidentiality, and then verbal/unsigned informed consent were obtained after clearing up verbal version of a consent form (information sheet) and subjects give their verbal consent in place of written consent to participate. Mothers who are unwilling were exempted from the study. Confidentiality was maintained anonymously and not communicated for other purposes.

\section{Consent to publish}


Not applicable.

\section{Availability of data and materials}

The datasets used and/or analyzed during the current study are available from the corresponding author on reasonable request. All relevant data supporting the current research investigation can be found in the manuscript.

\section{Competing interests}

The authors declare that they have no competing interests.

\section{Funding}

Wollo University contributed all financial need for the research.

\section{Authors' contributions}

The authors' responsibilities were as follows: TB and MA design the study, performed the statistical analysis, interpret the result and wrote the manuscript, and critically revised the manuscript, supervised the data collection process and approve quality of the data. All authors also highly participated in preparing and revising the final manuscript. The author(s) read and approved the final manuscript.

\section{Acknowledgements}

we would like to thank Wollo University, health Science College for arranging to conduct the study. We would like to express our deepest gratitude to all Mizan-Aman Sub-city administrative, kebele leaders, data collectors for their support and study participants involved in the study.

\section{References}

1. NEOVITA Study Group. Timing of initiation, patterns of breastfeeding, and infant survival: prospective analysis of pooled data from three randomized trials. Lancet Glob Health. 2016;4(4):e266-75.

2. United Nations Inter-Agency Group for Child Mortality Estimation (UNIGME). 'Levels \& Trends in Child Mortality: Report 2019, Estimates developed by the United Nations Inter-Agency Group for Child Mortality Estimation'. New York: United Nations Children's Fund; 2019.

3. Ethiopia M. Demographic and Health Survey (EMDHS),2019.

4. UNICEF, WHO. Capture the Moment - Early initiation of breastfeeding: The best start for every newborn. New York: UNICEF; 2018.

5. Victoria Cesar G, et al for The Lancet Breastfeeding Series Group. 'Breastfeeding in the 21st century: epidemiology, mechanisms, and lifelong effect'. Lancet. 2016;387:475-90. 
6. Rollins Nigel C, et al., The Lancet Breastfeeding Series Group. 'Why invest, and what it will take to improve breastfeeding practices?' Lancet, vol.387, 2016, pp. 491-504.

7. Chowdhury R, Sinha B, Sankar MJ, et al. Breastfeeding and maternal health outcomes: a systematic review and meta-analysis. Acta Paediatr. 2015;104:96-113.

8. Smith Emily R, et al. 'Delayed breastfeeding initiation and infant survival: A systematic review and meta-analysis.' PLoS ONE, vol, 12, no. 7, 25 July 2017.

9. McKenna KM, Shankar RT. the practice of prelacteal feeding to newborns among Hindu and Muslim families. J Midwifery Women's Health. 2009;54(1):78-81.

10. Sinha, Bireshwa, et al. 'Interventions to improve breastfeeding outcomes: systematic review and meta-analysis'. Acta Paediatr vol. December 2015;104, no.467:pp., 114-34.

11. Bbaale E. Determinants of early initiation, exclusiveness and duration of breastfeeding in Uganda. J Health Popul Nutr. 2014;32(2):249-60.

12. National strategy for Infant and Young Child Feeding (IYCF). Federal Ministry of Health. Family Health Department Ethiopia. 2004.

13. Federal Ministry of Health of Ethiopia. Health Sector Development Program IV (2010/11- 2014/15). 2010.

14. Government of the Federal Democratic Republic of Ethiopia. National Nutrition Programme Implementing Sectors Declaration: National Nutrition Programme; 2013-2015.

15. Central Statistical Agency (CSA) [Ethiopia] and ICF. Ethiopia Demographic and Health Survey 2016: Key Indicators Report. Maryland: Addis Ababa, Ethiopia, and Rockville; 2016.

16. Tilahun, et al. Prevalence and associated factors of timely initiation of breastfeeding among mothers at Debre Berhan town. International Breastfeeding Journal. 2016;11:27. DOI 10.1186/s13006-0160086-5.

17. Yaya, et al. Timely initiation of breastfeeding in Zimbabwe: evidence from the demographic and health surveys 1994- 2015 International Breastfeeding Journal (2020) 15:10.

18. Mekonen, et al. Timely initiation of breastfeeding and associated factors among mothers of infants under 12 months in South Gondar zone. International Breastfeeding Journal (2018) 13:17 https://doi.org/10.1186/s13006-018-0160-2.

19. Mussie Alemayehu K, Abreha H, Yebyo K, Zemichael. Hailay michael. Factors Associated with Timely Initiation Breast Feeding among Mothers of Axum Town, Northern Ethiopia. Science Journal of Public HealthVol. 2014;2(5):394-401. doi:10.11648/j.sjph.20140205.14.

20. Setegn, et al. Determinants of timely initiation of breastfeeding among mothers in Goba Woreda, South East Ethiopia. BMC Public Health. 2011;11:217. http://www.biomedcentral.com/14712458/11/217.

21. Nkoka, et al. Determinants of timely initiation of breast milk and exclusive breastfeeding in Malawi International Breastfeeding Journal, (2019) 14:37 https://doi.org/10.1186/s13006-019-0232-y. 
22. Belachew. Timely initiation of breastfeeding and associated factors among mothers of infants age 0-6 months old in Bahir Dar City, Northwest, Ethiopia, 2017 International Breastfeeding Journal, (2019) 14:5 https://doi.org/10.1186/s13006-018-0196-3.

23. Abie. and Goshu. Early initiation of breastfeeding and colostrum feeding among mothers of children aged less than 24 months in Debre Tabor, northwest Ethiopia BMC Res Notes (2019) 12:65 https://doi.org/10.1186/s13104-019-4094-6.

24. Tewabe. Timely initiation of breastfeeding and associated factors among mothers in Motta town. BMC Pregnancy Childbirth. 2016;16:314. DOI 10.1186/s12884-016-1108-4.

25. Yohannes E, Tesfaye T. Timely initiation of breastfeeding and associated factors among mothers who have infants less than six months of age in Gunchire Town, Southern Ethiopia 2019. Clin J Obstet Gynecol. 2020;3:026-32.

26. Woldemichael B, Kibie Y. Timely Initiation of Breastfeeding and Its Associated Factors among Mothers in Tiyo Woreda, Arsi Zone, Ethiopia: A Community- Based Cross Sectional Study. Clinics Mother Child Health. 2016;13:221. doi:10.4172/2090-7214.1000221.

\section{Figures}

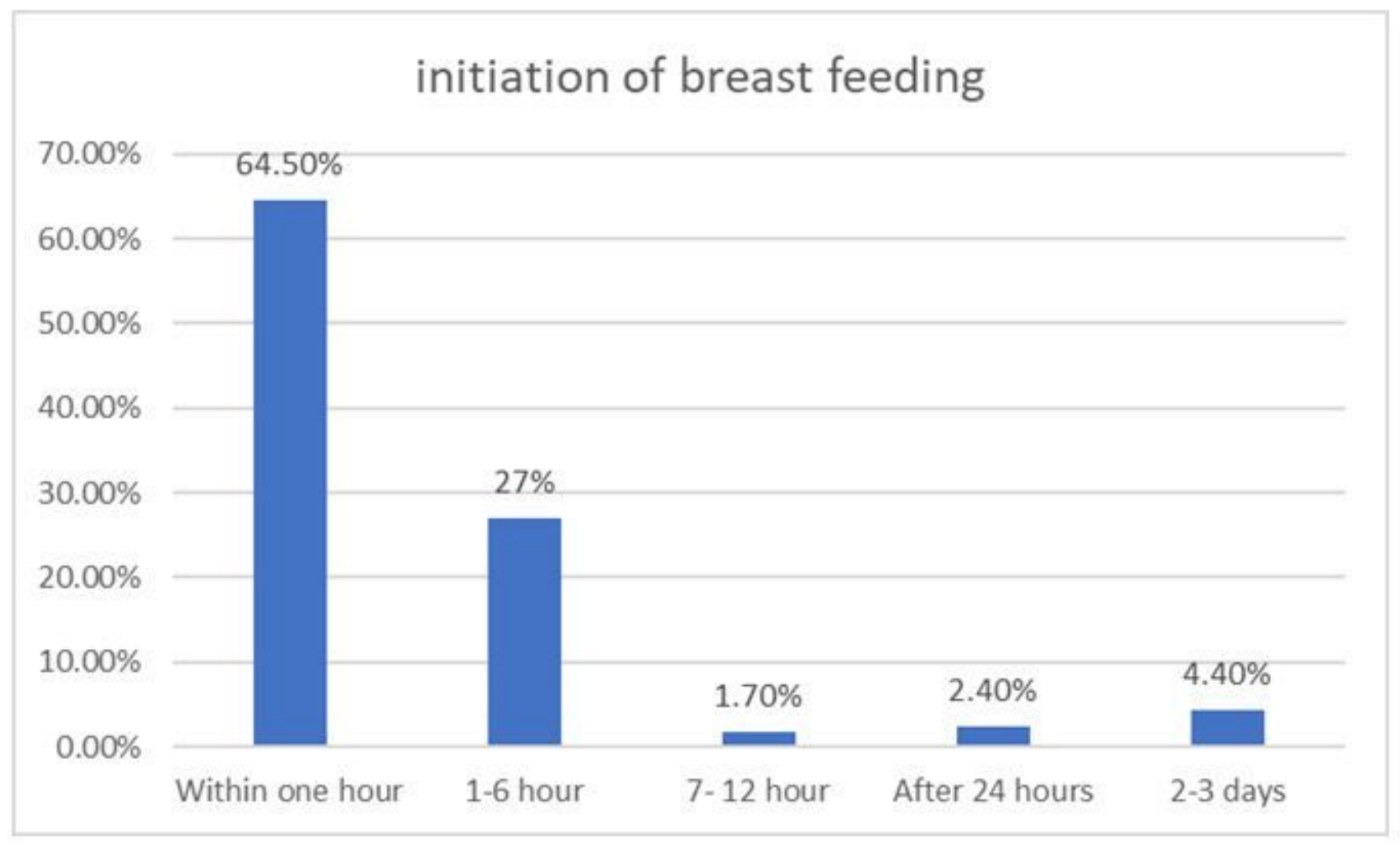

\section{Figure 1}

initiation of breast feeding among mothers of children's less than six months of age, Mizan-Aman town, southwest Ethiopia, 2018(N=459). 


\section{Supplementary Files}

This is a list of supplementary files associated with this preprint. Click to download.

- ElBFQuestionnaire.docx 